\title{
Insight into landslide kinematics from a broadband seismic network
}

\author{
Cheng-Horng Lin ${ }^{1,2,3}$
}

\begin{abstract}
The kinematic features of the 2009 Hsiaolin landslide were analyzed using a broadband seismic network in Taiwan. Both the final impact velocity and acceleration of the landslide were calculated based on the traveling distance and time of the landslide. A distance of approximately 2,500 $\mathrm{m}$ was observed on the surface, and the time from the initial collapse to the final impact was of $60.38 \mathrm{~s}$ according to broadband seismic data recorded nearby. The initial collapse time was determined using very-long-period seismic signals (20 to $50 \mathrm{~s}$ ) created by the elastic rebound of the shallow crust as the overlying landslide initially moved downhill. The final impact time was determined by detecting the largest amplitudes of high-frequency seismic signals (1 to $10 \mathrm{~Hz}$ ). The final impact velocity of approximately $298 \mathrm{~km} / \mathrm{h}$ exhibited by this landslide had never before been recorded and thus might mark a world record; these speeds can be attributed mainly to a low friction coefficient (approximately 0.12) and a long run-out (approximately 2,500 m) along a gentle dip-slope surface (approximately $15^{\circ}$ ).
\end{abstract}

Keywords: Hsiaolin landslide; Landslide kinematics; Impact velocity; Friction coefficient

\section{Correspondence/findings Introduction}

In 1970, a forceful high-speed debris avalanche in Peru triggered by an earthquake killed approximately 20,000 people (Schuster and Highland 2001). In general, the damage caused by catastrophic landslides depends on their size and velocity. The damage area typically depends on the landslide volume, whereas human survival is strongly influenced by the velocity; people can easily escape from the area affected by slow landslides, whereas they cannot escape from fast landslides. To classify the velocity of landslides, a 7-level scale was created by Cruden and Varnes (1996). Level 1 represents extremely slow landslides with speeds of less than $16 \mathrm{~mm} /$ year, whereas Level 7 represents extremely fast landslides with speeds higher than $5 \mathrm{~m} / \mathrm{s}(18 \mathrm{~km} / \mathrm{h})$. Some landslides even exceed this speed, but to determine the exact velocity of a landslide is difficult without reliable measures.

One of the most crucial parameters for determining the velocity of a landslide is the friction coefficient calculated according to the contact area that lies between the sliding

Correspondence: lin@earth.sinica.edu.tw

${ }^{1}$ Institute of Earth Sciences, Academia Sinica, P O Box 1-55, Nankang, Taipei, Taiwan

${ }^{2}$ Department of Geosciences, National Taiwan University, Taipei, Taiwan

Full list of author information is available at the end of the article material and the underlying layer. Less friction between the sliding material and the underlying layer engenders higher speeds. The friction coefficient typically depends on the materials, the textures of the surfaces, and given lubricants. Like the friction coefficient in the fault planes, the friction coefficient of rocks beneath landslides is a vital subject in the study of geodynamic processes (Sibson 1982; Scholz 1990; 1988). Determining whether an earthquake occurring along a fault plane exhibits high or low friction, it is interesting to know the seismogenic mechanism (Zoback et al. 1987). To determine friction coefficients along fault planes, the friction coefficients of various rock types have been measured in laboratories under simplified physical conditions (Dieterich 1978; Dieterich and Kilgore 1994; Blanpied et al. 1991). However, direct measurement of friction coefficients in the field remains difficult.

In this study, broadband seismic data were collected to analyze the Hsiaolin landslide, which occurred in Taiwan on August 8, 2009 and was one of the fastest landslides recorded worldwide. The friction coefficient of the contact area between the sliding material and underlying layer was retrospectively estimated by considering both the run-out distance and travel time. 


\section{Hsiaolin landslide}

On 8 August 2009, Typhoon Morakot landed on Taiwan and several hundreds of large, deep-seated landslides were triggered by extremely heavy rainfall (Lin et al. 2010). The most catastrophic of the landslides buried 474 residents in the village of Hsiaolin, southern Taiwan (Lin et al., 2010). Careful geological survey of the Hsiaolin landslide (Tsou et al. 2011) revealed that the major slide materials initially collapsed from an elevation of approximately 1,280 $\mathrm{m}$ (Hsindoshan) and were then deposited along Chishan Creek at an elevation of approximately $450 \mathrm{~m}$ (Figure 1). As the landslide moved downhill and reached an elevation of $590 \mathrm{~m}$, it separated into two major parts that continued to move in different directions. The southern landslide affected highland regions at an elevation of $590 \mathrm{~m}$ and then buried all houses in the northern part of Hsiaolin Village, killing most of the residents immediately. The northern landslide moved along the gully and halted at Chishan Creek. Consequently, the landslide immediately formed a dam. After approximately 40 min later, the debris flow due to the dam breach flushed away the remaining houses, except two that were situated on the highland in the southern part of Hsiaolin Village (Chen et al. 2011).

\section{Broadband seismic data}

Like most of the large landslides that occurred on 8 August 2009, the Hsiaolin landslide (Lin et al. 2010) generated valuable seismic data, namely very-long-period seismic signals (20 to $50 \mathrm{~s}$; Figure 2a), which were well recorded by the broadband array in Taiwan for seismology (BATS) (Kao et al. 1998). The propagating velocity of the very-longperiod signals measured approximately $3.4 \mathrm{~km} / \mathrm{s}$, which is characteristic of typical surface waves on the earth. These very-long-period signals could propagate along distances of more than 2,000 km (Lin et al. 2010). By contrast, some of the high-frequency seismic signals (1 to $10 \mathrm{~Hz}$ ) with a propagating velocity of approximately $5 \mathrm{~km} / \mathrm{s}$ were detected only at nearby stations, at distances of less than $100 \mathrm{~km}$ (Figure 2b). These high-frequency seismic signals were probably the P-waves propagated in the crust; thus, they decayed substantially as the distance increased.

Of the many broadband seismic stations in Taiwan, Station TPUB, which is located approximately $12.5 \mathrm{~km}$ north of the location of the Hsiaolin landslide (Figure 3a), recorded valuable seismic signals, including the first clear arrivals of the very-long-period signals (20 to $50 \mathrm{~s}$ ). These signals were measured at $22 \mathrm{~h} 16 \mathrm{~min} 13.1 \mathrm{~s}$ on 8 August (Greenwich Mean Time), or 6:00 AM, 9 August (local
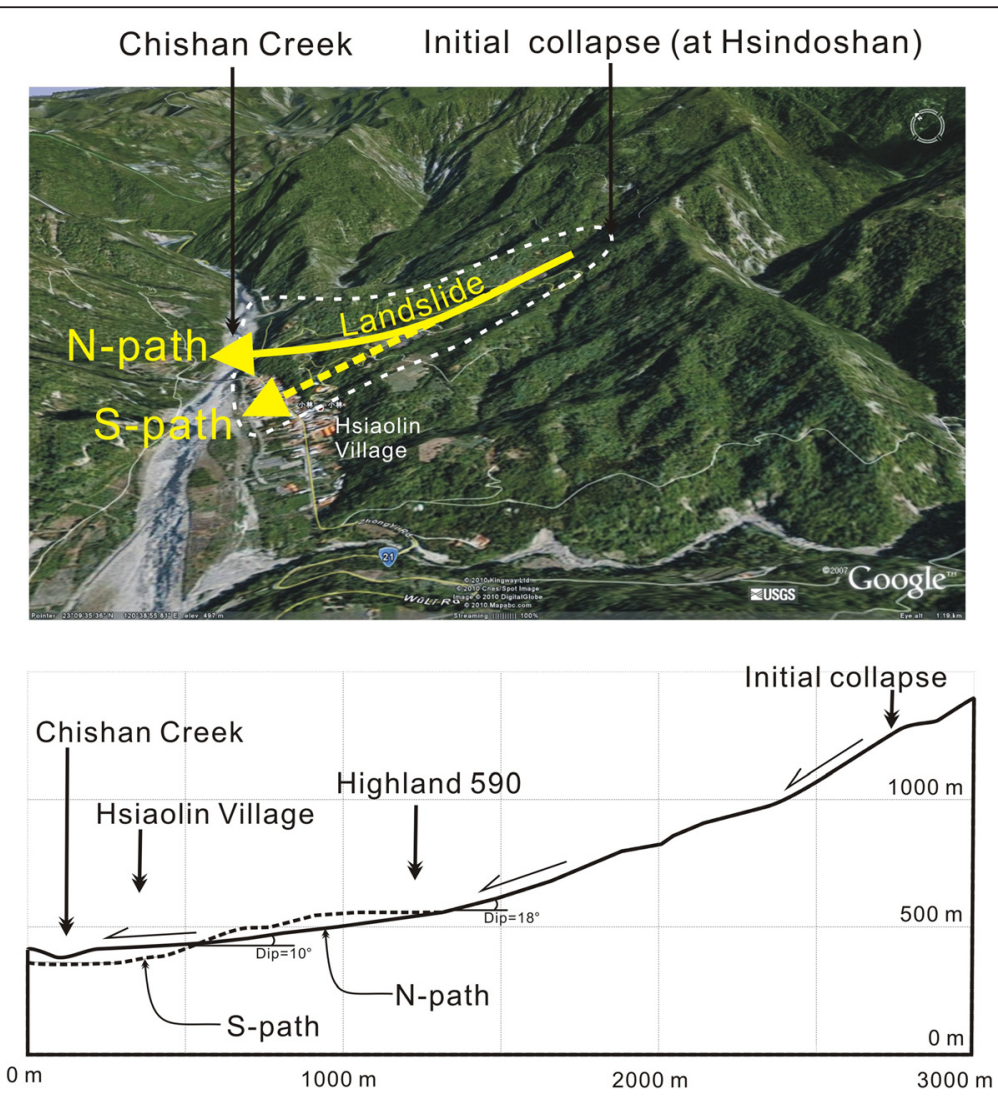

Figure 1 Topographic map showing the two major paths of the Hsiaolin landslide. 
(a) Long-period signals $(20-50 \mathrm{~s})$

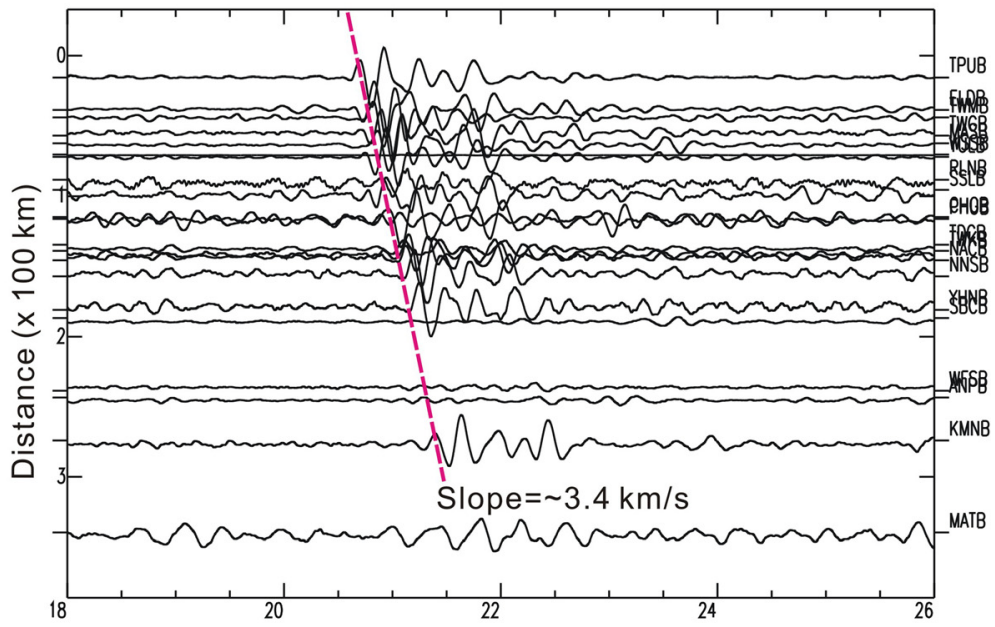

(b) High-frequency signals $(1-10 \mathrm{~Hz})$

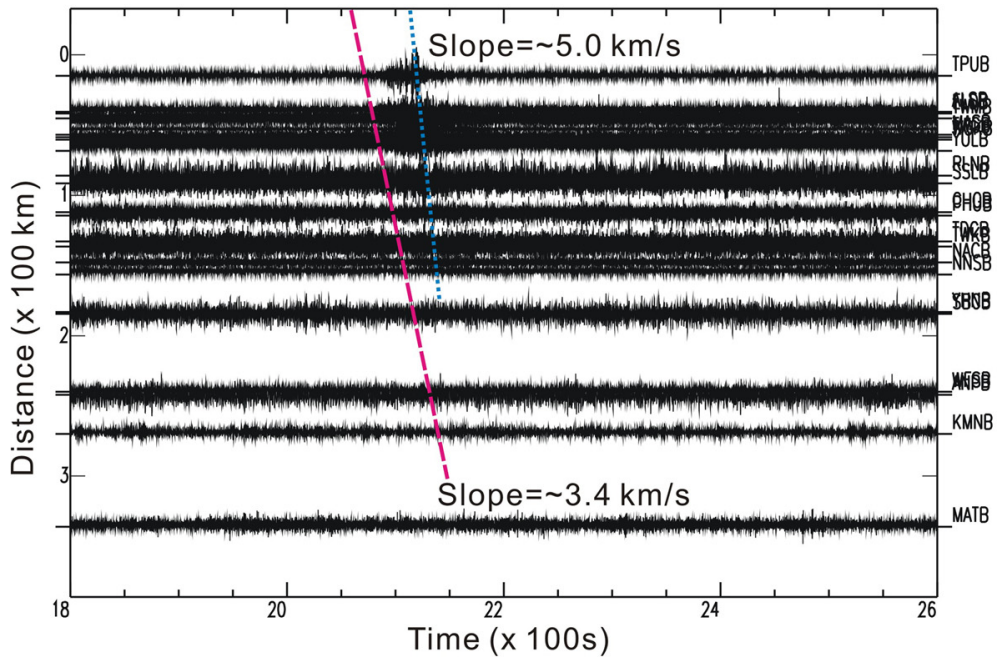

Figure 2 Seismograms generated by the Hsiaolin landslide. Seismograms recorded at broadband seismic stations in Taiwan and filtered using a bandpass of (a) 20 to $50 \mathrm{~s}$ and (b) 1 to $10 \mathrm{~Hz}$. The slopes of the very-long-period seismic signals (broken red line) and high-frequency signals (dotted blue line) indicate the velocities of the surface waves (approximately $3.4 \mathrm{~km} / \mathrm{s}$ ) and P-waves (approximately $5 \mathrm{~km} / \mathrm{s}$ ), respectively.

time) (Figure 3b). However, the exact occurrence time of the landslide was starting at $22 \mathrm{~h} 16 \mathrm{~min} 9.42 \mathrm{~s}$ if one considered the traveled time of $3.68 \mathrm{~s}$ from the landslide to the seismic station at a distance of $12.5 \mathrm{~km}$ by given a propagated seismic velocity of $3.4 \mathrm{~km} / \mathrm{s}$. A possible mechanism underlying the very-long-period signals is elastic rebound from the shallow crust after the landslide started (Kanamori and Given 1982; Kawakatsu 1989). The rebound theory is also consistent with the observations obtained from various large-scale landslide experiments (Moriwaki et al. 2004) that clearly showed that overlying materials are bent downward by the gravitational force of the sliding material before the material moves downhill (Figure 4). Thus, elastic rebound of the shallow crust might have been caused immediately after the landslide occurred. The very-long-period signal clearly arrived considerably earlier than any other high-frequency seismic waves $(1$ to $10 \mathrm{~Hz}$ ) generated by the landslide (Figure $3 \mathrm{~b}$ ).

The seismic amplitudes of the high-frequency signals $(1$ to $10 \mathrm{~Hz}$ ) recorded at Station TPUB increased in the first minute after the initial collapse and then decreased subsequently (Figure $3 \mathrm{~b}$ ). This pattern might represent the entire process of landslide movement. It is assumed that high-frequency seismic energy was largely released from the impact of the sliding momentum on a barrier or a particularly rough surface. A stronger impact generates seismic energy with a larger amplitude. At the early stage, small seismic amplitudes were generated by the slowly moving landslide, exhibiting low momentum; as the landslide accelerated, it generated larger seismic amplitudes. 


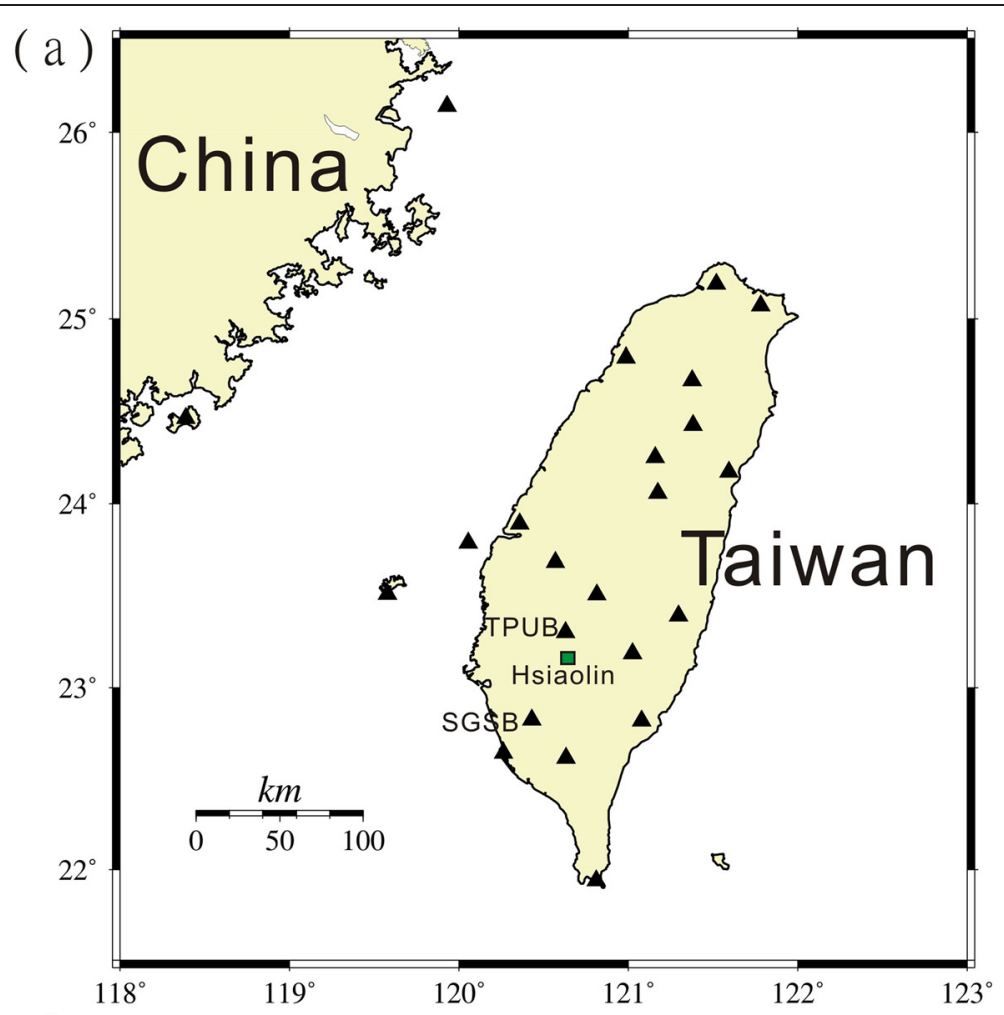

( b )

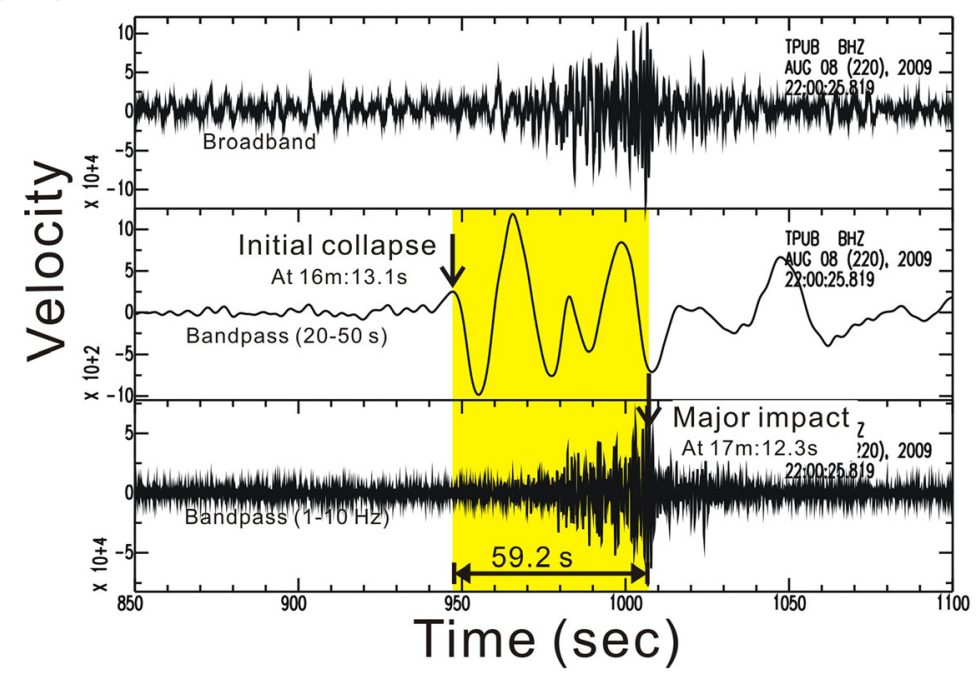

Figure 3 Seismic station distribution and seismograms recorded at Station TPUB. (a) Locations of broadband seismic stations in Taiwan (triangles) and the Hsiaolin landslide (square). (b) Broadband seismograms (top) and band pass filtered by 20 to $50 \mathrm{~s}$ (middle) and 1-10 Hz (bottom) and recorded at Station TPUB, which lies approximately $12.5 \mathrm{~km}$ north of the location of the Hsiaolin landslide.

The high-frequency seismic signals exhibited the largest amplitude at $17 \mathrm{~min} 12.3 \mathrm{~s}$ at station TPUB, likely marking the time when the major part of the landslide hit and then stopped at Chishan Creek (Figure 4). However, the exact impact time of the landslide was reduced to $22 \mathrm{~h} 17 \mathrm{~min}$ $9.8 \mathrm{~s}$ if one considered the traveled time of $2.5 \mathrm{~s}$ from the landslide to the seismic station at a distance of $12.5 \mathrm{~km}$ by given a propagated seismic velocity of $5.0 \mathrm{~km} / \mathrm{s}$. Thus, the final impact of the landslide occurred approximately 60.38 $\mathrm{s}$ after the very-long-period seismic signals were first detected, indicating the initiation of the Hsiaolin landslide. Although some high-frequency signals were detected after 


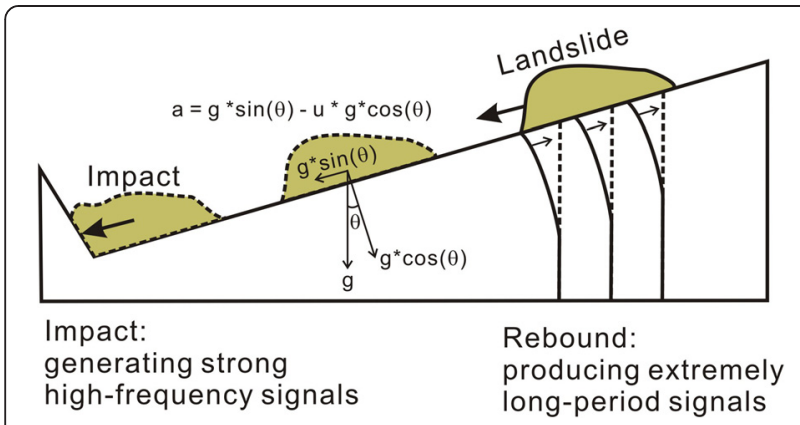

Figure 4 Schematic diagram illustrating landslide kinematics. The elastic rebound as the landslide collapsed, producing verylong-period seismic signals, and the final impact, generating strong high-frequency signals. The acceleration of a moving landslide results from both the gravitational and the frictional force of the sliding surface.

the landslide produced its major impact, they might have been generated by subsequent landslides.

\section{Landslide kinematics}

Various crucial kinematic parameters of the Hsiaolin landslide can be derived by combining the obtained seismic data with detailed field survey data. First, the acceleration of the sliding materials can be estimated using the measurements of the run-out distance and the traveling time obtained from the broadband seismic data. Although the total distance of the landslide, from the crown of the collapsed area at an elevation of $1,380 \mathrm{~m}$ to the deposition area near Chishan Creek, was approximately 3,200 m (Tsou et al. 2011), the average run-out distance of most of the landslide material, from the center of the collapsed area to Chishan Creek, might be only approximately 2,500 $\mathrm{m}$ (Kou et al. 2011). The time required to cover the average run-out distance (60.38 s) can be estimated using measurements of both the very-long-period seismic signals $(20$ to $50 \mathrm{~s}$ ) and high-frequency (1 to $10 \mathrm{~Hz}$ ) signals. Thus, when the distance and time are known, the average acceleration of the Hsiaolin landslide can be calculated using the following kinematic equations.

$$
D=0.5 \times a \times t^{2} \text { and } V=a \times t
$$

where $a, V, D$, and $t$ are the acceleration, velocity, runout distance, and traveling time of the moving block, respectively. The average acceleration of the landslide was approximately $1.37 \mathrm{~m} / \mathrm{s}^{2}$, and the final impact velocity was $82.81 \mathrm{~m} / \mathrm{s}$ (or approximately $298 \mathrm{~km} / \mathrm{h}$ ).

In addition to the velocity and acceleration of the Hsiaolin landslide, the coefficient of friction between the sliding material and the overlying ground surface can be calculated using a simple kinetic equation commonly used in physics (Figure 4).

$$
a=g \times \sin (\theta)-u \times g \times \cos (\theta),
$$

where $a$ is the acceleration of the moving block, $g$ is the gravitational acceleration $\left(980 \mathrm{~cm} / \mathrm{s}^{2}\right), u$ is the friction coefficient, and $\theta$ is the inclination of the slope. Thus, the coefficient of friction beneath the moving material is only approximately 0.12 , given an average inclination of $15^{\circ}$ in the major landslide profile, although the inclination exhibits gradual variations in the range of $10^{\circ}$ to $20^{\circ}$ (Figure 1 ).

\section{Discussion}

A velocity as high as that of the Hsiaolin landslide (approximately $298 \mathrm{~km} / \mathrm{h}$ ) had not been reported anywhere in the world prior to 2009. A high-velocity landslide of that scale is difficult to observe unless it can be predicted. The factors contributing to such a landslide includes a low friction coefficient, long run-out distance, and gentle dip-slope ground surface. The friction coefficient of the Hsiaolin landslide (approximately 0.12) is lower than that of most comparable landslides and debris flows (Scheidegger 1973; Brodsky et al. 2003). This low friction coefficient was can be attributed mainly to extremely heavy rainfall, which infiltrated the space between the sliding material and the overlying ground. In addition, the long run-out distance of approximately 2,500 m resulted from a gentle dip-slope surface extending from Hsindoshan to Chishan Creek. The dip slope has an average incline of approximately $15^{\circ}$, and the inclination varies from $10^{\circ}$ to $20^{\circ}$. Consequently, the major portion of the collapsed landslide moved downhill smoothly until it reached the Chishan creek.

It is difficult to fathom the devastation caused by the Hsiaolin landslide when it reached Chishan Creek and Hsiaolin Village. Approximately, $25 \times 10^{6} \mathrm{~m}^{3}$ of debris (Tsou et al. 2011) slid down the slope at a maximal speed of approximately $298 \mathrm{~km} / \mathrm{h}$ and destroyed all structures and buildings.

\section{Conclusion}

This detailed study of the 2009 Hsiaolin landslide in Taiwan demonstrated that the kinematic parameters of a landslide, such as the velocity $(298 \mathrm{~km} / \mathrm{h})$ and acceleration $\left(1.37 \mathrm{~m} / \mathrm{s}^{2}\right)$, can be derived directly from broadband seismic data. The starting time of the landslide was obtained from the very-long-period seismic signals (20 to $50 \mathrm{~s}$ ) generated by the elastic rebound of the shallow crust beneath the landslide, whereas the end of the landslide was estimated using the largest amplitude of the short-period seismic signals produced by the impact on Chishan Creek. The results revealed that the velocity at the time of the final impact reached approximately $298 \mathrm{~km} / \mathrm{h}$, equaling 
the speed of the fastest high-speed trains and constituting a landslide velocity that had previously not been reported. In addition, the friction coefficient of the landslide was 0.12. Such low friction can be attributed mainly to extremely heavy rainfall, which infiltrated the space between the sliding materials and the overlying ground.

\section{Competing interests}

The author declares that he has no competing interests.

\section{Acknowledgments}

The author would like to thank both the Ministry of Science and Technology (MOST) as well as the Center of Sustainability Science, Academia Sinica, Taipei, Taiwan for the financial support. The data provided by the Institute of Earth Sciences, Academia Sinica, and the Central Weather Bureau, Taipei, Taiwan as well as the Google earth map are appreciated.

\section{Author details}

${ }^{1}$ Institute of Earth Sciences, Academia Sinica, P O Box 1-55, Nankang, Taipei, Taiwan. ${ }^{2}$ Department of Geosciences, National Taiwan University, Taipei, Taiwan. ${ }^{3}$ National Center for Research on Earthquake Engineering, National Applied Research Laboratories, Taipei, Taiwan.

Received: 26 July 2014 Accepted: 24 December 2014

Published online: 17 January 2015

\section{References}

Blanpied ML, Lockner DA, Byerlee JD (1991) Fault stability inferred from granite sliding experiments at hydrothermal conditions. Geophys Res Lett 18:609-612

Brodsky EE, Gordeev E, Kanamori H (2003) Landslide basal friction as measured by seismic waves. Geophys Res Lett 30:2236, doi: 10.1029/2003GL018485

Chen CC, Dong JJ, Kuo CY, Hwang RD, Li MH, Lee CT (2011) Reconstruction of the kinematics of landslide and debris flow through numerical modelling supported by multidisciplinary data: the 2009 Siaolin, Taiwan landslide, sediment transport - flow and morphological processes, F. Bhuiyan (Ed.).

Cruden DM, Varnes DJ (1996) Landslide types and processes. In Landslides, Investigation and Mitigation. Special Report 247, Transportation Research Board, Washington, pp 36-75

Dieterich J (1978) Time dependent friction and the mechanics of stick slip. Pure Appl Geophys 116:790-806

Dieterich JH, Kilgore B (1994) Direct observation of frictional contacts: new insights for state-dependent properties. Pure Appl Geophys 143:283-302

Kanamori H, Given JW (1982) Analysis of long-period seismic waves excited by the May 18, 1980, eruption of Mount St. Helens - A terrestrial monopole? J Geophys Res 87:5422

Kao H, Jian PR, Ma KF, Huang BS, Liu CC (1998) Moment-tensor inversion for offshore earthquakes east of Taiwan and their implications to regional collision. Geophys Res Lett 25:3619-3622

Kawakatsu H (1989) Centroid single force inversion of seismic waves generated by landslides. J Geophys Res 94:12363-12374

Kou CY, Tsai YC, Chen CC, Chang KJ, Siau AY, Dong JJ, Han RH, Shimamoto T, Lee CT (2011) The landslide stage of the Hsiaolin catastrophe: simulation and validation. J Geophys Res 116:F04007, doi: 10.1029/2010JF001921

Lin CH, Kumagai H, Ando M, Shin TC (2010) Detection of landslides and submarine slumps using broadband seismic networks. Geophys Res Lett 37:L22309, doi: 10.1029/2010GL044685

Moriwaki H, Inokuchi T, Hattanji T, Sassa K, Ochiai H, Wang G (2004) Failure processes in a full-scale landslide experiment using a rainfall simulator. Landslides 1:277-288, doi: 10.1007/s10346-004-0034-0

Scheidegger AE (1973) On the prediction of the reach and velocity of catastrophic landslides. Rock Mech 5:231-236

Scholz CH (1990) The mechanics of earthquakes and faulting. Cambridge University Press, 439pp Cambridge, New York

Scholz CH (1988) Earthquakes and friction laws. Nature 391:37-42, doi:10.1038/ 34097
Schuster RL, Highland LM (2001) Socioeconomic and environmental impacts of landslides in the western hemisphere. U.S. Geological Survey open-file report $01-0276$.

Sibson RH (1982) Fault zone models, heat flow, and the depth distribution of earthquakes in the continental crust of the United States. Bull Seismol Soc Am 72:151-163

Tsou CY, Feng ZY, Chigira M (2011) Catastrophic landslide induced by Typhoon Morakot, Shiaolin, Taiwan. Geomorphology 127:166-178

Zoback MD, Zoback ML, Mount VS, Suppe J, Eaton JP, Healy JH, Oppenheimer D, Reasenberg P, Jones L, Raleigh CB, Wong IG, Scotti O, Wentworth C (1987) New evidence on the state of stress of the San Andreas fault system. Science 238:1105-1111

\section{Submit your manuscript to a SpringerOpen ${ }^{\odot}$ journal and benefit from:}

- Convenient online submission

- Rigorous peer review

- Immediate publication on acceptance

- Open access: articles freely available online

- High visibility within the field

- Retaining the copyright to your article

Submit your next manuscript at $>$ springeropen.com 